\title{
The Effects of the Aerobics Exercise Program on the Cardiopulmoner Capacity and Disease Symptoms of the Patients with Primary Fibromialgia Syndrome*
}

\author{
Berat Meryem Alkan ${ }^{1 \#}$, Sumru Özel ${ }^{2}$, Serap Tomruk Sütbeyaz ${ }^{2}$, Canan Çulha ${ }^{2}$ \\ ${ }^{1}$ Atatürk Education and Research Hospital, PMR Clinic, Ministry of Health, Ankara, Turkey; ${ }^{2}$ Ankara Physical Medicine and \\ Rehabilitation Education and Research Hospital, PMR Clinic, Ministry of Health, Ankara, Turkey. \\ Email: "berat.alkan@ttmail.com
}

Received August $2^{\text {nd }}, 2013$; revised September $2^{\text {nd }}, 2013$; accepted September $9^{\text {th }}, 2013$

Copyright (C) 2013 Berat Meryem Alkan et al. This is an open access article distributed under the Creative Commons Attribution License, which permits unrestricted use, distribution, and reproduction in any medium, provided the original work is properly cited.

\begin{abstract}
Backgrounds: To observe the effects of aerobic exercise program on the illness symptoms and cardiopulmonary capacity of the patients with primary Fibromyalgia Syndrome (FMS) and to find out whether there is a difference or not in terms of cardiovascular capacity among the patients with primary FMS and sedentary healthy people. Materials and Methods: The study has been done on 20 female patients with primary FMS. Before the study and after a 6-week controlled aerobic exercise program, a cardiopulmonary exercise test has been applied on all cases. The symptoms, psychological state and life quality of the cases have been evaluated before and after the exercise program. The first cardiopulmonary results of the cases with FMS have been compared with a control group of 15 sedentary healthy. Results: When the patient and control groups are compared, although maksimal oxygen uptake ( $\mathrm{VO} 2 \mathrm{max}$ ) was lower in the patient group, this was not a significant difference. $\mathrm{VO} 2$ max showing the aerobic condition after the exercise increased significantly in the patients. Conclusions: Aerobic exercise programs lasting six to eight weeks are quite effective for the patients with FMS. There is not any limitation in the increase of the cardiopulmonary capacity of the patients after the exercise program.
\end{abstract}

Keywords: Aerobic Exercise; Cardiopulmonary Capacity; Primary Fibromyalgia Syndrome

\section{Introduction}

Fibromyalgia syndrome (FMS) is a chronic form of nonarticular rheumatism characterized by widespread pain, stiffness, and multiple tender points. It is regarded as part of a spectrum of chronic widespread pain [1]. The etiopathogenesis remains unknown. Physical exercise has been found to be an effective intervention strategy for long term management of FMS. McCain et al. and Wigers et al. found that aerobic physical exercise improves not only the cardiovascular fitness but also raises the pain threshold scores of trained patients with FMS [2,3].

There are too many studies about medical treatment of FMS, which is a multidimensional chronic disease, but effects of exercise on FMS is an inert area. Aim of our

\footnotetext{
*This article was presented at 5th Mediterranean Congress of Physical and Rehabilitation Medicine, 2004, Antalya (Poster Presentation). Conflict of interest: No conflict of interest is declared by authors.

\#Corresponding author.
}

study is to determine cardiopulmonary capacity of FMS patients, and investigate the effects of regular aerobic exercise program on cardiopulmonary capacity and disease symptoms.

\section{Materials and Methods}

In this cross-sectional, randomized study, 24 female patients who were diagnosed with FMS according to the criteria of the 1990 American Rheumatology Association and a group of 15 sedentary healthy control group with similar demographic characteristics were included. Our study planned on the 24 patients with fibromyalgia, but 4 patients did not continue to aerobic exercise program, was completed on 20 patients. All FMS patients were newly diagnosed. All of them were nonsmoking women. Patients and controls had no history of any respiratory or cardiac disease. They were not on current therapy (pharmacologic or physical training); and had no history of 
any systemic or rheumatic disease, malignant or infective disease, or trauma.

Before application of the test, 12 derivation computerised ECG of all cases were recorded, and ECG was monitorised during the test. Blood pressure levels were measured and recorded both before and during each phase of the test. For cardiopulmonary exercise test, a computerised system (Sensor Medix Vmax 29), which increases the resistance progressively, posseses electronic brake system, connected to treadmill, collects and analyses the gases given off during the exercise, monitorizes ECG and vital signs was used. System, which is composed of a mask, bidrectional respiratory valve, a round spirometer, and a $\mathrm{O} 2$ and $\mathrm{CO} 2$ analyser was calibrated according to known gas concentrations and volume before each test. Gases given off were analysed in every 20 seconds.

As cardiopulmanory exercise test parameters, maksimal oxygen uptake $=\mathrm{VO} 2 \max (\mathrm{ml} / \mathrm{kg} / \mathrm{min})$, heart rate: (HR) (beat $/ \mathrm{min}), \mathrm{O} 2$ pulse (ml/beat), minute ventilation (VE max (1/min)), tidal volume (VT), respiratory rate (RR), breathing reserve (\%), dead space-tidal volume ratio (VD/VT rest), respiratory quotient (RQ) (VCO2/ $\mathrm{VO} 2)$ ), oxygen saturation ( $\mathrm{Sp} \mathrm{O} 2)$ and exercise period were measured and anaerobic treshold (AT) presence was established in both patient and control group.

Test was terminated when patient was exhausted, had chest pain or any other cardiovasculary symptom, severe dyspnea, blood pressure change within limits of physiological answer to exercise, and pathological alteration in ECG monitorization. ECG and blood pressure were monitorized till baseline levels after exercise.

Exercise program: After maxiumum oxygen uptake was measured with cardiovascular exercise test; following the 3 minutes of warming up in treadmill, maximum exercise level of the patient according to modified Bruce protocole was determined [4]. Starting with one step lower level of the patients' maximum exercise level, speed and incline of the treadmill was improved gardually according to modified Bruce protocole as long as patient was able to continiue the test. All cases attended the programme for 30 minutes, three times a week for 6 weeks, in cardiopulmonary rehabilitation unit in Ankara Physical Medicine and Rehabilitation Education and Research Hospital. Paitents were not allowed to use medication for analgesia. Ergospirometric tests were repeated after aerobic exercise program.

The symptoms, psychological state and life quality of the cases have been evaluated before and after the exercise program that they joined. Pain level, fatigue, sleep quality, a global self-evaluation of the patient and the global evaluation of the doctor has been measured by
VAS. In addition, the number of his sensitive points and the duration of her morning paralyzation have been recorded. Beck depression inventory, State-Trait Anxiety Inventory (STAI Form TX-1 and STAI Form TX-2) and SF-36 have been applied. Aim of Beck depression inventory is a not to diagnose depression, it is a self evaluated scale to determine the level of depression [5]. Symptoms objectively. SF-36 is composed of 36 items evaluating 8 subscales. These subscales are physical function, physical role, pain, global health, vitality, social function, emotional role, mental health. Score range is in between 0 100, higher scores meaning higher quality of life [6].

Statistical analysis: Entry and exit of patients, evenly spaced and the rate of the data obtained from the normal distribution and homogeneity of the variations were examined. These types of scale data obtained from the parametric tests (Student t-test) was applied. Classification and sorting of the data type obtained from the nonparametric tests (Wilcoxon test and $\mathrm{X}^{2}$ test) was applied. Pearson correlation analysis was used to assess the correlation of parameters with each other. The relationship between these variables as well as with multiple stepwise regression analysis were examined. Related analysis was conducted using SPSS 10.0 package program.

\section{Results}

The first cardiopulmonary results of the cases with fibromialgia have been compared with a control group of 15 sedentary healthy people who were similar in terms of age, sex, and mass body index.

When the patient and control groups are compared, although VO2 max was lower in the patient group, this was not a meaningful difference VO2 max showing the aerobics condition after the exercise increased significantly in the patients. In cardiopulmonary exercise test, there was no considerable difference in VO2 max, 02 pulse \%, VE max, VT, RR, Breathing reserve, RQ ve $\mathrm{SpO} 2$ between patient and controls; but HR max and exercise period were found to be significantly lower in FMS group (Table 1).

Repeated cardiopulmonary exercise test parameters were compared to pre-exercise parameters. Considerable improvement was observed in VO2 max, 02 pulse \%, VE max, VT Respiratory rate (RR), HR max, HR reserve and exercise period scores when compared to pretreatment scores. ( $\mathrm{P}<0.05)$ (Table 2$)$.

In all the obseved clinical parameters as pain, number of sensitive points, morning stiffness duration, fatigue, sleep and depression a significant recovery has been discovered (Table 3). Both self evaluated and physician evaluated global VAS scores showed significant reduc- 
Table 1. Comparison of ergospirometric parameter of patients and controls.

\begin{tabular}{cccc}
\hline Parameter & Patient group $(\mathrm{n}=24)$ & Control group $(\mathrm{n}=15)$ & $\mathrm{P}$ value \\
\hline Maksimal oxygen uptake (VO2 max) $(\mathrm{ml} / \mathrm{kg} / \mathrm{min})$ & $19.88 \pm 5.04(12-28)$ & $21.27 \pm 6.53(10.60-31.80)$ & $(\mathrm{t}=0.747)(\mathrm{P}=0.460)$ \\
02 pulse \% (ml/beat) & $8.19 \pm 1.61(5.03-11.47)$ & $8.27 \pm 2.12(3.93-11.87)$ & $(\mathrm{t}=0.131)(\mathrm{P}=0.896)$ \\
Minute ventilation (VE max) (1/min) & $62.08 \pm 15.11(30.5-90.3)$ & $62.91 \pm 16.40(39.30-89.30)$ & $(\mathrm{t}=0.161)(\mathrm{P}=0.873)$ \\
Tidal volume (VT) & $1.43 \pm 0.25(0.93-1.87)$ & $1.40 \pm 0.26(1.02-1.84)$ & $(\mathrm{t}=-0.405)(\mathrm{P}=0.688)$ \\
Respiratory rate (RR) & $37.62 \pm 10.90(4-57)$ & $38.46 \pm 9.73(27-62)$ & $(\mathrm{t}=0.244)(\mathrm{P}=0.809)$ \\
Breathing reserve (BR) & $74.68 \pm 16.51(33.5-94.4)$ & $72.68 \pm 15.42$ & $(\mathrm{t}=-0.378)(\mathrm{P}=0.708)$ \\
Respiratory quotient (RQ) & $1.13 \pm 0.09(0.94-1.33)$ & $1.08 \pm 0.10(0.80-1.21)$ & $(\mathrm{t}=-1.467)(\mathrm{P}=0.151)$ \\
Oxygen saturation (SpO2) & $81.95 \pm 16.70(8-94)$ & $85.73 \pm 3.47(81-92)$ & $(\mathrm{t}=0.860)(\mathrm{P}=0.395)$ \\
Maksimum heart rate (HR max) (beat $/ \mathrm{min})$ & $159.50 \pm 20.54(118-191)$ & $169.13 \pm 9.84(150-182)$ & $(\mathrm{t}=-2.413)(\mathrm{P}=0.026)^{*}$ \\
Exercise time & $14.55 \pm 2.23(10.29-19.15)$ & $16.17 \pm 2.12(12-20)$ & $(\mathrm{t}=2.245)(\mathrm{P}=0.031)^{*}$ \\
\hline
\end{tabular}

*statically significant $(\mathrm{P}<0.05)$.

Table 2. Comparison of preexercise and postexercise ergospirometric parameters of FMS patients.

\begin{tabular}{cccc}
\hline Parameters & Preexercise $(\mathrm{n}=20)$ & Postexercise $(\mathrm{n}=20)$ & $\mathrm{P}$ values \\
\hline Maksimal oxygen uptake (VO2 max) $(\mathrm{ml} / \mathrm{kg} / \mathrm{min})$ & $19.13 \pm 5.06(12-26.5)$ & $22.59 \pm 4.19(14.6-31.8)$ & $(\mathrm{t}=-4.194) \mathrm{P}=0.000)^{*}$ \\
02 pulse (ml/beat) & $8.15 \pm 1.73(5.03-11.47)$ & $8.91 \pm 1.56(6.81-12.91)$ & $(\mathrm{t}=-2.174) \mathrm{P}=0.043)^{*}$ \\
Minute ventilation (VE max) (1/min) & $58.99 \pm 14.06(30.50-84)$ & $67.99 \pm 12.14(51.5-90)$ & $\left(\mathrm{t}=-3.579(\mathrm{P}=0.002)^{*}\right.$ \\
Tidal volume (VT) & $1.38 \pm 0.24(0.93-1.77)$ & $1.55 \pm 0.19(1.15-1.78)$ & $(\mathrm{t}=-3.242)(\mathrm{P}=0.004)^{*}$ \\
Respiratory rate (RR) & $38.50 \pm 7.91(27-54)$ & $41.20 \pm 7.61(27-54)$ & $(\mathrm{t}=-2.941)(\mathrm{P}=0.008)^{*}$ \\
Breathing reserve (BR) & $72.39 \pm 16.57(33.5-93.4)$ & $76.16 \pm 11.82(55-96)$ & $(\mathrm{t}=-1.224)(\mathrm{P}=0.236)$ \\
Dead space-tidal volume ratio (VD/VT rest) & $0.54 \pm 0.06(0.45-0.65)$ & $0.50 \pm 0.07(0.27-0.66)$ & $(\mathrm{t}=1.783)(\mathrm{P}=0.091)$ \\
Maksimum heart rate (HR max) & $155.25 \pm 19.53$ & $165.20 \pm 12.97$ & $(\mathrm{t}=-2.413)(\mathrm{P}=0.026)^{*}$ \\
Heart rate reserve (HR reserve) & $14.45 \pm 15.89(0-41)$ & $5.10 \pm 7.93(0-34)$ & $(\mathrm{t}=2.501)(\mathrm{P}=0.022)^{*}$ \\
Exercise time & $14.29 \pm 2.34(10.29-19.15)$ & $17.16 \pm 1.77(14-20.11)$ & $(\mathrm{t}=-7.529)(\mathrm{P}=0.000)^{*}$ \\
\hline
\end{tabular}

*statically significant $(\mathrm{P}<0.05)$.

tion at the end of the treatment programme $(\mathrm{P}<0.001)$. When patients' sleep problems were evaluated with VAS, we observed statistically significant improvement (Table 3). Besides, patients' frequent awakening and difficulty in falling into sleep problems before and after the treatment program were compared. Patients' nightly awakening frequency substantially decreased $(\mathrm{z}=-2.91, \mathrm{P}=$ $0.004)$. number of the days patients had problem in falling into sleep in a week also decreased significantly $(\mathrm{z}=$ $-3.109, \mathrm{P}=0.002)$. Patients' fatigue levels were evaluated with VAS and Likert scale. At the end of the study VAS scores improved significantly $(\mathrm{t}=3.34, \mathrm{P}=0.003)$ (Table 3). İmprovement in Likert scale was also significant $(z=-4.001, P=0.000)$. Again, at the end of the study, patients reported that they felt more rested when ther woke up in the morning $(\mathrm{P}<0.001)$. No significant change was observed in trait anxiety and continiunity concerns scores after treatment $(\mathrm{P}>0.05)$. Pain, physical role, social function and emotional role in the SF-36 life quality scale have demostrated a considerable improvement (Table 4).

In correlation analysis after the study, in patient group, there was significant correlation between improvement in pain VAS scores after exercise and; improvement in fatigue VAS, self and physician evaluated global VAS, VO2 max, O2 pulse and VT parameters. Again, there was significant correlation between increase in VO2 max scores and; pain VAS, self and physician evaluated 
Table 3. In patients with FMS compared preexercise and postexercise clinical parameters.

\begin{tabular}{cccc}
\hline Clinic characteristics & Preexercise $(\mathrm{n}=20)$ & Postexercise $(\mathrm{n}=20)$ & $\mathrm{P}$ values \\
\hline Pain score (VAS) & $7.80 \pm 1.47$ & $3.40 \pm 2.18$ & $(\mathrm{t}=9.426)(\mathrm{P}=0.000)^{*}$ \\
Stiffness (dk) & $17.35 \pm 14.52$ & $6.45 \pm 6.06$ & $(\mathrm{t}=3.498)(\mathrm{P}=0.00)^{*}$ \\
Number of sensitive points & $14.05 \pm 2.06$ & $8.70 \pm 2.53$ & $(\mathrm{t}=10.84)(\mathrm{P}=0.000)^{*}$ \\
Fatigue (VAS) & $8.30 \pm 1.41$ & $4.90 \pm 1.94$ & $(\mathrm{t}=9.48)(\mathrm{P}=0.000)^{*}$ \\
Sleep problem (VAS) & $4.55 \pm 2.28$ & $2.80 \pm 2.21$ & $(\mathrm{t}=3.34)(\mathrm{P}=0.003)^{*}$ \\
Depression & $15.30 \pm 6.79$ & $10.60 \pm 6.76$ & $(\mathrm{t}=5.454)(\mathrm{P}=0.000)^{*}$ \\
\hline
\end{tabular}

"statically significant $(\mathrm{P}<0.05)$.

Table 4. Comparison of preexercise and postexercise SF-36 parameters of FMS patients.

\begin{tabular}{cccc}
\hline SF-36 & Patient group $(\mathrm{n}=20)$ (Preexercise) & Patient group $(\mathrm{n}=20)$ (Postexercise) & $\mathrm{P}$ values \\
\hline Physical function & $64.50 \pm 13.56$ & $69.75 \pm 13.61$ & $(\mathrm{t}=-1.458)(\mathrm{P}=0.161)$ \\
Physical role & $25.00 \pm 35.35$ & $47.50 \pm 34.31$ & $(\mathrm{t}=-3.454)(\mathrm{P}=0.003)^{*}$ \\
Pain & $39.50 \pm 12.76$ & $49.50 \pm 17.31$ & $(\mathrm{t}=-2.437)(\mathrm{P}=0.025)^{*}$ \\
General health & $46.00 \pm 18.60$. & $44.16 \pm 18.21$. & $(\mathrm{t}=-0.664)(\mathrm{P}=0.515)$ \\
Vitality & $41.25 \pm 16.27$ & $42.75 \pm 11.75$. & $(\mathrm{t}=-0.525)(\mathrm{P}=0.606)$ \\
Social function & $61.31 \pm 21.50$ & $77.50 \pm 16.01$ & $(\mathrm{t}=-3.336)(\mathrm{P}=0.003)^{*}$ \\
Emotional role & $39.82 \pm 41.35$ & $73.31 \pm 33.52$ & $(\mathrm{t}=-4.014)(\mathrm{P}=0.001)^{*}$ \\
Mental health & $61.00 \pm 11.40$. & $56.60 \pm 11.40$ & $(\mathrm{t}=1.509)(\mathrm{P}=0.148)$ \\
\hline
\end{tabular}

global VAS, physical role and trait anxiety scores in SF-36 scale, HR max, O2 pulse, VE max, VT, Breathing reserve, RQ parameters, and improvement in exercise period (Table 5).

\section{Discussion}

Difficulty of the endurance exercises and its effects on body are evaluated by oxygen consumption. In other words, maximal oxygen consumption (VO2 max) most important indicator of increase in cardiovascular capacity is increase in oxygen intake amount. In studies about fibromyalgia syndrome, aerobic capacities of the patients and observed improvements are usually measured by this parameter. In our study, insignificant lower values of VO2 maximum in fibromyalgia patients showed decreased aerobic capacity when compared to sedantary healthy controls. Similar results were reported in other studies $[7,8]$. Valim et al. found that VO2 max, AT and maximal HR levels were significantly lower in FMS patients compared to healthy controls [9]. In their study Bennet et al. compared the data of American Heart Association (AHA) on the VO2 max of normal population to fibromyalgia patients. Results show that $80 \%$ of fibromyalgia patients are below average aerobic condition level [7].
Another recent parameter used to evaluate the cardio respiratory compliance is anaerobic treshold (AT) [10]. The AT can be defined as the largest oxygen uptake reached without sustained lactacidosis. It can be measured either directly by lacticemia dosage or indirectly by analysis of expired gases. The aerobic-anaerobic transition may serve as a basis for individually assessing endurance performance as well as for prescribing intensities in endurance training [11]. AT, although used less than VO2 Max, is also a good physical fitness indicator, and it has the advantage of not being maximum effort dependent, i.e., it does not depend on the individual's will to cooperate, like fibromyalgia or patients with cardiovascular disease [12]. It seems to be more influenced by training than VO2 max and represents a safer intensity for exercise. During cardiopulmanory exercise test, rate of AT was $95 \%$ in our patient group and $93.3 \%$ in control group. After exercise program, retest results showed, again, rate of $95 \%$ AT in patient group. It was observed that patient groups' time interwal to AT was shorter.

In cardiopulmanory exercise test, patient group had significant lower exercise period when compared to normal controls, this suggests that inactivity and deconditioning in fibromyalgia patients limit peak exercise capa- 
Table 5. Improvement in parameters related to improvement in pain VAS and VO2 max and P values in Pearson correlation analysis.

\begin{tabular}{ccc}
\hline Imrovement (I) in parameters & Improvement in pain VAS & Improvement in maksimal oxygen uptake (IVO2 max) \\
\hline Improvement in pain VAS & $(\mathrm{r}=1.000)$ & $(\mathrm{r}=0.548, \mathrm{P}=0.012)^{*}$ \\
Improvement in VO2 max (IVO2 max) & $(\mathrm{r}=0.548, \mathrm{P}=0.012)^{*}$ & $(\mathrm{r}=1.000)$ \\
Improvement in fatique VAS & $(\mathrm{r}=0.469, \mathrm{P}=0.037)^{*}$ & $(\mathrm{r}=-0.021, \mathrm{P}=0.931$ \\
Improvement in self evaluated global VAS & $(\mathrm{r}=0.549, \mathrm{P}=0.012)^{*}$ & $(\mathrm{r}=0.507, \mathrm{P}=0.022)^{*}$ \\
Improvement in physician evaluated global VAS & $(\mathrm{r}=0.511, \mathrm{P}=0.021)^{*}$ & $\mathrm{r}=0.508, \mathrm{P}=0.022)^{*}$ \\
Improvement in physical role & $(\mathrm{r}=0.091, \mathrm{P}=0.703)$ & $(\mathrm{r}=0.506, \mathrm{P}=0.023)^{*}$ \\
Improvement in trait anxiety & $(\mathrm{r}=-0.342, \mathrm{P}=0.139)$ & $(\mathrm{r}=-0.483, \mathrm{P}=0.031)^{*}$ \\
Improvement in maksimum heart rate & $(\mathrm{r}=0.073, \mathrm{P}=0.759)$ & $(\mathrm{r}=0.601, \mathrm{P}=0.005)^{*}$ \\
İmprovement in heart rate reserve & $(\mathrm{r}=-0.084, \mathrm{P}=0.724)$ & $(\mathrm{r}=-0.583, \mathrm{P}=0.007)^{*}$ \\
Improvement in O2 pulse & $(\mathrm{r}=0.490, \mathrm{P}=0.028)^{*}$ & $(\mathrm{r}=0.662, \mathrm{P}=0.001)^{*}$ \\
Improvement in Minute ventilation & $(\mathrm{r}=0.424, \mathrm{P}=0.062)$ & $(\mathrm{r}=0.770, \mathrm{P}=0.000)^{*}$ \\
Improvement in Tidal volum & $(\mathrm{r}=0.515, \mathrm{P}=0.020)^{*}$ & $(\mathrm{r}=0.888, \mathrm{P}=0.000)^{*}$ \\
Improvement in breathing reserve & $(\mathrm{r}=0.278, \mathrm{P}=0.236)$ & $(\mathrm{r}=0.673, \mathrm{P}=0.001)^{*}$ \\
Improvement in respiratory quotient & $(\mathrm{r}=0.134, \mathrm{P}=0.572$ & $(\mathrm{r}=0.604, \mathrm{P}=0.005)^{*}$ \\
Improvement in exercise time & $(\mathrm{r}=0.132, \mathrm{P}=0.578)$ & $(\mathrm{r}=0.535, \mathrm{P}=0.015)^{*}$ \\
\hline
\end{tabular}

${ }^{*}$ statically significant $(\mathrm{P}<0.05)$.

city. Test was terminated due to fatigue in $80 \%$ of patients and due to cardiovascular intolerance in $20 \%$ of patients. This suggests that pysical deconditioning in fibromyalgia patients is an important factor limiting exercise capacity.

With Data from an appropriate exercise test, we can determine activity levels that minimise potential cardiac risks and maximise physical performance and helpful cardiac precautions can be set. when we repeated the cardiopulmanory tests of patients after aerobic exercise program for 6 weeks, 3 times a week for 30 minutes on treadmill, we observed significant improvement in ergospirometric parameters. When compared to pretreatment scores, substancial improvement was observed in VO2 max, O2 pulse \%, VE max, VT, RR, HR max levels, HR reserve and exercise period $(\mathrm{P}<0.05)$ (Figures 1 and 2 ).

Increase in maximal oxygen uptake and anaerobic treshold is physiological effect of exercise. Increase in aerobic capacity occurs with peripheral and central mechanisms $[13,14]$. In our study, after exercise program all of the patients showed increase in cardiopulmonary capacity, prominently in VO2 max and exercise period. This result shows that low capacity in fibromyalgia patients can be increased by exercise, thus, indirectly shows that, fibromyalgia is not a disorder due to primary muscle pa- thology and is due to secondary deconditioning state. In our patients, we observed these physiological adaptation mechanisms in a short duration of 6 weeks. As aerobic capacity of the patients increased significantly, we also observed increase in HR max levels when compared to pretreartment vaules. Also HR reserve improved significantly. Reduction in VE max and BR are frequently used parameters to evaluate the presence of vantilatory limitation for exercise. Increase in VE max and BR levels after exercise show us that there is no underlying ventilatory pathology. Increase in VD/VT ratio, which is indicator of ventilatory insufficiency, frequently dead space ventilation, also decreased. These results support the notion that there is no cardiovascular or peripheral limitation in FMS.

Improvement was observed in al clinical parameters like pain, tender point count, morning stiffness, fatigue and depression. Significant improvement was observed in pain, physical role, social function and emotional role subscales of SF-36 scale. Favorable effects of regular aerobic activity in FMS patients on pain [2], total myalgia score $[3,15]$, tender point count $[14,16]$, fatigue [15], quality of life $[17,18]$, depression and anxiety $[14,19]$ are reported.

In our study, sleep disturbances were evaluated with 


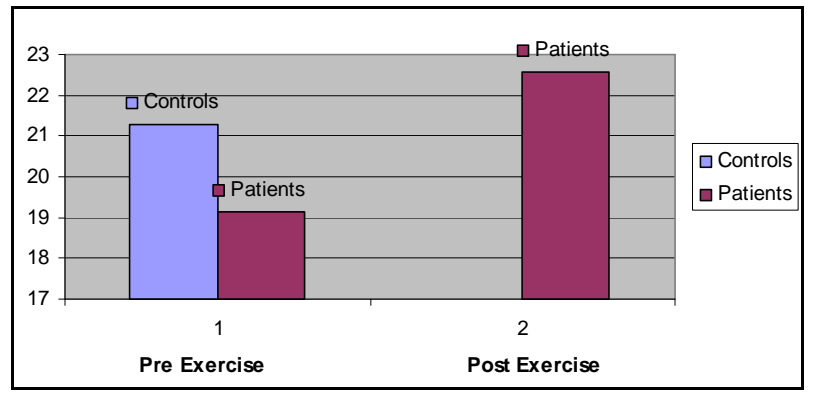

Figure 1. VO2 Max values in patients and controls.

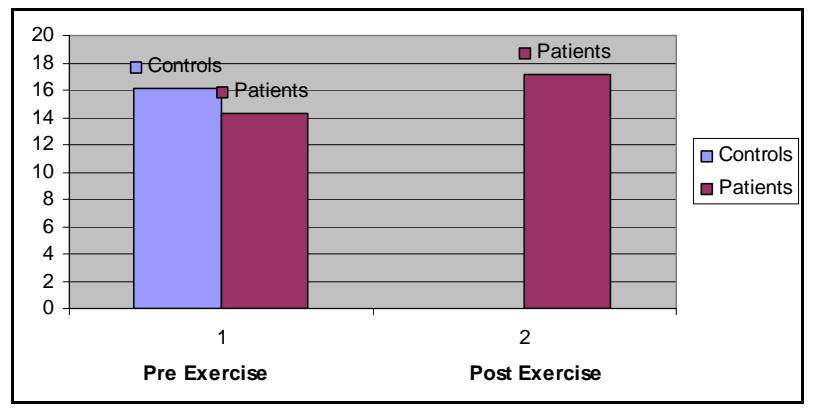

Figure 2. Exercise time in patients and controls.

VAS, also how many times they woke up in a nightsleep, number of the days they had problem falling into sleep in a week and whether they felt fatigue when they woke up in the morning or not were questioned. After 6 weeks' long exercise program, all these scores improved significantly. There are only a few controlled studies about effects of aerobic exercise on sleep disturbances of FMS patients $[2,20]$.

When we analysed the correlation between increase in cardiopulmonary capacity and improvement of clinical parameters; we observed considerable correlation between self-evaluated and physician evaluated global VAS and physical role subscale of SF-36 which both evaluate pain. Valim et al. in their study compared stretch exercise group to aerobic exercise group and reported substancial increase in $\mathrm{VO} 2$ max and AT levels in aerobic exercise group. They reported no correlation between cradiorespiratory improvement and increase in quality of life; between increase in $\mathrm{VO} 2$ and $\mathrm{AT}$ and clinical symptoms of FMS [21].

Aerobic exercises are accepted as standard treatment in FMS. What discussed debate is duration and intensity of aerobic exercise. Many studies reported favorable effects of intense aerobic exercise programs $[3,16]$. Ramsay $\mathrm{C}$ et al. reported moderate improvement in shortterm, but no significant improvement and patient compliance in long term results of their study in which they applied 12 weeks long mild exercise program. They attributed this insignificant improvement to the low intensity level of exersice program [19]. Again, no improve- ment was observed in pain and other clinical parameters in another study of 6 months long low intensity fitness program [22]. On the contrary, many studies report that intense exercise programs have unfavorable effects on pain and fatigue; low intensity, repeating sets of exercises may be more beneficial $[23,24]$. We suggest that, based both on our study and other intense controlled program studies; controlled-short duration aerobic fittness programs to increase endurance in moderate intensity are more effective than uncontrolled low intensity exercise programs. Our results show that 6 weeks long exercise sessions are sufficient. To preserve the improvement on symptoms and condition, exercises should be continiued regularly, but in low intensity and frequency.

\section{Conclusion}

Controlled and average concentration aerobics exercise programs lasting six weeks are quite effective for the patients with FMS. There is not any limitation in the increase of the cardiopulmonary capacity of the patients after the exercise program.

\section{REFERENCES}

[1] W. Hauser, C. Zimmer, E. Felde and V. Köllner, "What Are the Key Symptoms of Fibromyalgia Syndrome? Results of a Survey of the German Fibromyalgia Association," Schmerz, Vol. 22, No. 2, 2008, pp. 176-183.

[2] G. A. McCain, D. A. Bell and F. M. Mai and P. D. Halliday, "A Controlled Study of the Effects of a Supervised Cardiovasküler Fitness Training Program on the Manifestations of Primary Fibromyalgia," Arthritis \& Rheumatism, Vol. 3, No. 9, 1988, pp. 1135-1141. http://dx.doi.org/10.1002/art.1780310908

[3] S. H. Wigers, T. C. Stiles and P. A. Vogel, "Effects of Aerobic Exercise versus Stres Manegement Treatment in Fibromyalgia. A 4.5 Year Prospective Study," Scandinavian Journal of Rheumatology, Vol. 25, No. 2, 1996, pp. 77-86. http://dx.doi.org/10.3109/03009749609069212

[4] L. A. Kaminsky and M. H. Whaley, "Evaluation of a New Standardized Ramp Protocol: The BSU/Bruce Ramp Protocol," Journal of Cardiopulmonary Rehabilitation, Vol. 18, No. 6, 1998, pp. 438-444. http://dx.doi.org/10.1097/00008483-199811000-00006

[5] A. T. Beck, R. A. Steer and G. K. Brown, "BDI-II Manual," Psychological Corporation, San Antonio, 1996.

[6] R. D. Hays, C. D. Sherbourne and R. M. Mazel, "The RAND 36-Item Health Survey 1.0," Health Econ, Vol. 2, No. 3, 1993, pp. 217-277. http://dx.doi.org/10.1002/hec.4730020305

[7] R. M. Bennett, S. R. Clark, L. Goldberg, D. Nelson, R. P. Bonafede, J. Porter, et al., "Aerobic Fitness in Patients with Fibrositis," Arthritis \& Rheumatism, Vol. 32, No. 4, 1989, pp. 454-460. http://dx.doi.org/10.1002/anr.1780320415 
[8] K. E. Sietsema, D. M.Cooper and X. Caro, "Oxygen Uptake during Exercise in Patients with Primary Fibromyalgia Syndrome," Journal of Rheumatoloyg, Vol. 20, No. 5, 1993, pp. 860-865.

[9] V. Valim, L. M. Oliveira, A. L. Suda, L. E. Silva, M. Faro and T. L. Neto, et al., "Peak Oxygen Uptake and Ventilatory Anaerobic Threshold in Fibromyalgia," Journal of Rheumatology, Vol. 29, No. 2, 2002, pp. 353-357.

[10] M. C. Lemos, V. Valim, E. Zandonade and J. Natour, "Intensity Level for Exercise Training in Fibromyalgia by Using Mathematical Models," BMC Musculoskelet Disorder, Vol. 11, No. 54, 2010, pp. 2-6.

[11] O. Faude, W. Kindermann and T. Meyer, "Lactate Threshold Concepts: How Valid Are They?" Sports Medicine, Vol. 39, No. 6, 2009, pp. 469-490. http://dx.doi.org/10.2165/00007256-200939060-00003

[12] A. Koike, K. Wasserman, K. Tanigushi, M. Hiroe and F. Marumo, "The Critical Capillary PO2 and the Lactate Threshold in Patients with Cardiovascular Disease," Journal of the American College of Cardiology, Vol. 23, No. 7, 1994, pp. 1644-1650.

[13] N. Bölükbaş1, "Kardiyak Rehabilitasyon,” In: M. Beyazova and Y. Gökçe-Kutsal, Eds., Fiziksel Tip ve Rehabilitasyon, Vol. 1, 2000, pp. 1142-1157.

[14] M. Dinler, D. Diracoglu, E. Kaşıkcıŏlu, Ö. Saylı, A. Akın, C. Aksoy, et al., "Effect of Aerobic Exercise Training on Oxygen Uptake and Kinetics in Patients with Fibromyalgia," Rheumatology International, Vol. 30, No. 2, 2009, pp. 281-284. http://dx.doi.org/10.1007/s00296-009-1126-x

[15] C. S. Burckhardt, K. Mannerkorpi, L. Hedenberg and A. Bjelle, "A Randomized Controlled Clinical Trial of Education and Physical Training for Women with Fibromyalgia," The Journal of Rheumatology, Vol. 21, No. 4, 1994, pp. 714-720.

[16] L. Martin, A. Nutting, B. R. Macintosh, S. M. Edworthy, D. Butterwick and J. Cook, "An Exercise Program in the Treatment of Fibromyalgia," The Journal of Rheuma- tology, Vol. 23, No. 6, 1996, pp. 1050-1053.

[17] J. E. Naschitz, M. Rozenbaum, I. Rosner, E. Sabo, R. M. Priselac, N. Shaviv, et al., "Cardiovasküler Response to Upright Tilt in Fibromyalgia Differ from That in Chronic Fatigue Syndrome," The Journal of Rheumatology, Vol. 28, No. 6, 2001, pp. 1356-1360.

[18] R. O. Gervais, A. S. Russell, P. Gren, L. M. Allen, R. Ferrari and S. D. Pieschl, "Effort Testing in Patients with Fibromyalgia and Disabilite İncentives," The Journal of Rheumatology, Vol. 28, No. 8, 2001, pp. 1892-1898.

[19] C. Ramsay, J. Moreland, M. Ho, S. Joyce, S. Walker and T. Pullar, "An Observer-Blinded Comparison of Supervised and Unsupervised Aerobic Exercise Regimens in Fibromyalgia," Rheumatology, Vol. 39, No. 5, 2000, pp. 501505. http://dx.doi.org/10.1093/rheumatology/39.5.501

[20] L. Altan, U. Bingöl, M. Aykaç, Z. Koç and M. Yurtkuran, "Investigation of the Effects of Pool-Based Exercise on Fibromyalgia Syndrome," Rheumatological International, Vol. 24, No. 5, 2004, pp. 272-277.

[21] V. Valim, L. M. Oliveira, A. Suda, L. Silva, M. de Assis Barros, T. Neto, et al., "Aerobic Fitness in Fibromyalgia," The Journal of Rheumatology, Vol. 30, No. 5, 2003, pp. 1060-1069.

[22] M. Van Santen, P. Bolwijn, F. Verstappen, C. Bakker, A. Hidding, H. Houben, et al., "A Randomized Clinical Trial Comparing Fitness and Biofeedback Training versus Basic Treatment in Patients with Fibromyalgia," The Journal of Rheumatology, Vol. 29, No. 3, 2002, pp. 575-581.

[23] S. J. King, J. Wessel, Y. Bhambhani, D. Sholter and W. Maksymowych, "The Effects of Exercise and Education, İndividually or Combined, in Women with Fibromyalgia," The Journal of Rheumatology, Vol. 29, No. 12, 2002, pp. 2620-2627.

[24] M. Van Santen, P. Bolwijn, R. Landewe, et al., "High or Low İntensity Aerobic Fitness Training in Fibromyalgia: Does İt Matter," Journal of Rheumatology, Vol. 29, No. 3, 2002, pp. 582-587. 